\title{
Erratum to: Critical examination of recent assertions by Logo (2013) about the paper 'Analytical and numerical solutions for a reliability based benchmark example' (Rozvany and Maute 2011)
}

\author{
George Rozvany • Kurt Maute
}

Published online: 31 October 2013

(C) Springer-Verlag Berlin Heidelberg 2013

Erratum to: Struct Multidisc Optim (2013)

DOI 10.1007/s00158-013-0989-3

The aim of this Corrigendum is to point out a type-setting error in Fig. 4 of the above Authors' Reply, which was not caused by the authors.

\section{Statement of the type-setting error}

Figure 4 as it has been typeset erroneously:

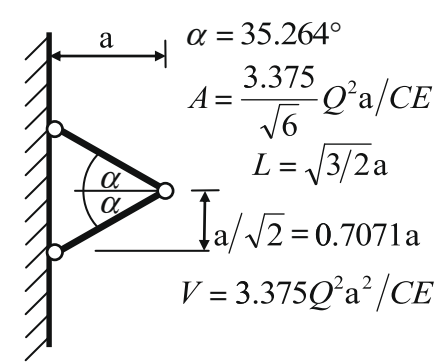

(a)

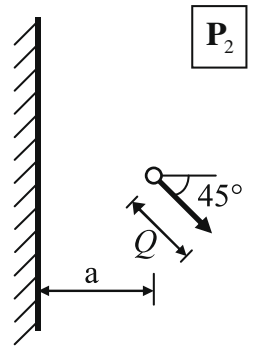

(b)

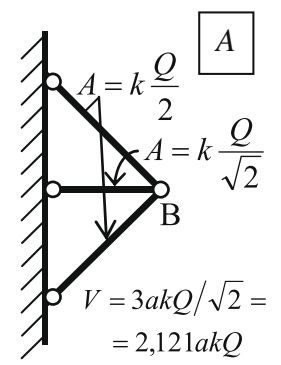

(c)

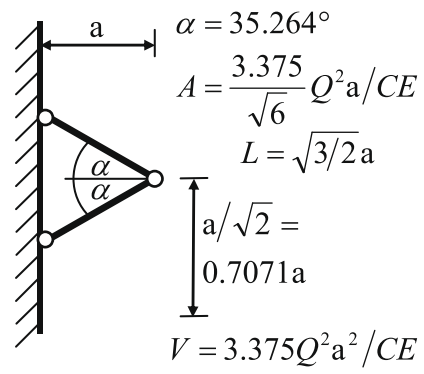

(d)

The online version of the original article can be found at http://dx.doi.org/10.1007/s00158-013-0989-3.

G. Rozvany $(\bowtie)$

Department of Structural Mechanics,

Budapest University of Technology and Economics,

Müegyetem rkpt 3, Kmf 63, 1111 Budapest, Hungary

e-mail:smo.rozvany@t-online.hu

\section{K. Maute}

Department of Aerospace Engineering Sciences,

University of Colorado,

Boulder, CO, USA

e-mail: kurt.maute@colorado.edu 
Figure 4 as it should have been typeset:

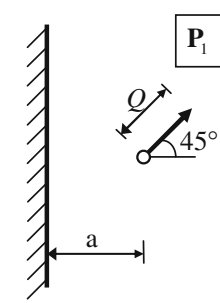

(a)

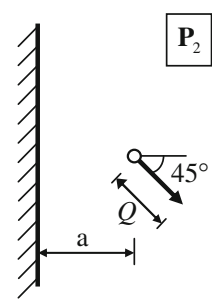

(b)

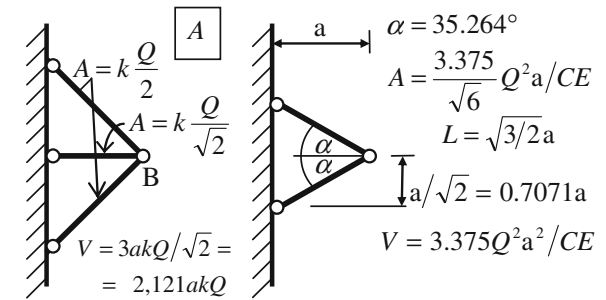

(c)

(d) 